\title{
Atoxigenic Aspergillus flavus Isolates Endemic to Almond, Fig, and Pistachio Orchards in California with Potential to Reduce Aflatoxin Contamination in these Crops
}

\author{
Alejandro Ortega-Beltran, ${ }^{1, \dagger}$ Juan Moral, ${ }^{1}$ Adeline Picot, ${ }^{1}$ Ryan D. Puckett, ${ }^{1}$ Peter J. Cotty, ${ }^{2}$ and Themis J. Michailides ${ }^{1, \dagger}$ \\ ${ }^{1}$ Department of Plant Pathology, University of California, Davis, and Kearney Agricultural Research and Extension Center, Par- \\ lier, CA 93648; and ${ }^{2}$ United States Department of Agriculture-Agricultural Research Service, School of Plant Sciences, The Uni- \\ versity of Arizona, Tucson, AZ 85721
}

\begin{abstract}
In California, aflatoxin contamination of almond, fig, and pistachio has become a serious problem in recent years due to long periods of drought and probably other climatic changes. The atoxigenic biocontrol product Aspergillus flavus AF36 has been registered for use to limit aflatoxin contamination of pistachio since 2012 and for use in almond and fig since 2017. New biocontrol technologies employ multiple atoxigenic genotypes because those provide greater benefits than using a single genotype. Almond, fig, and pistachio industries would benefit from a multi-strain biocontrol technology for use in these three crops. Several A. flavus vegetative compatibility groups (VCGs) associated with almond, fig, and pistachio composed exclusively of atoxigenic isolates, including the VCG to which AF36 belongs to, YV36, were previously characterized

in California. Here, we report additional VCGs associated with either two or all three crops. Representative isolates of 12 atoxigenic VCGs significantly $(P<0.001)$ reduced $(>80 \%)$ aflatoxin accumulation in almond and pistachio when challenged with highly toxigenic isolates of $A$. flavus and $A$. parasiticus under laboratory conditions. Isolates of the evaluated VCGs, including AF36, constitute valuable endemic, well-adapted, and efficient germplasm to design a multi-crop, multi-strain biocontrol strategy for use in tree crops in California. Availability of such a strategy would favor long-term atoxigenic A. flavus communities across the affected areas of California, and this would result in securing domestic and export markets for the nut crop and fig farmer industries and, most importantly, health benefits to consumers.
\end{abstract}

Aflatoxins are toxic fungal secondary metabolites that cause negative health effects, including death, in both humans and domestic animals (CAST 2003; Liu et al. 2012; Probst et al. 2007). These mycotoxins are produced by fungi belonging to Aspergillus section Flavi, including Aspergillus flavus and A. parasiticus (Amaike and Keller 2011; Cotty et al. 1994). Among the four major aflatoxins $\left(B_{1}, B_{2}, G_{1}\right.$, and $\left.G_{2}\right)$, aflatoxin $B_{1}$ is both most toxic and most prevalent and is classified as a Group 1 carcinogen by the International Agency for Research on Cancer (IARC 2002). In developed nations, enforcement of regulations prohibiting commercialization of food and feed exceeding aflatoxin tolerance levels is common (van Egmond et al. 2007;

Present address of A. Ortega-Beltran: International Institute of Tropical Agriculture, PMB 5320 Oyo Road, Ibadan, Nigeria.

Present address of J. Moral: Departamento de Agronomía, ETSIAM, Universidad de Córdoba, Campus de Rabanales, Córdoba, Spain.

Present address of A. Picot: Université de Brest, EA 3882, Laboratoire Universitaire de Biodiversité et Ecologie Microbienne, IBSAM, ESIAB, Technopôle Brest-Iroise, 29280 Plouzané, France.

${ }^{\dagger}$ Corresponding authors: A. Ortega-Beltran; E-mail: a.beltran@cgiar.org; and T. J. Michailides; E-mail: tjmichailides@ucanr.edu

Funding: We thank the California Pistachio Research Board (CPRB-AFLAMichailides-2015 and CPRB-AFLA-Michailides-2016), the Almond Board of California (15-AFLA1-Michailides and 16-AFLA1-Michailides), and the California Fig Institute for financial support of this project. A. OrtegaBeltran received a Consejo Nacional de Ciencia y Tecnología-Mexico scholarship (Estancia postdoctoral en el extranjero, 237422). J. Moral received an H2020 Marie Skłodowska-Curie Actions fellowship launched by the European Union (contract number 658579).

The author(s) declare no conflict of interest.

Accepted for publication 25 October 2018.

@ 2019 The American Phytopathological Society
$\mathrm{Wu}$ 2004). The European Union allows aflatoxin $B_{1}$ at a maximum concentration of $8 \mu \mathrm{g} / \mathrm{kg}$ and total aflatoxins at $10 \mu \mathrm{g} / \mathrm{kg}$ in almond and pistachio intended for direct human consumption (van Egmond et al. 2007) while, in the United States, total aflatoxin content of a maximum of $20 \mu \mathrm{g} / \mathrm{kg}$ is allowed in pistachio and almond (Food and Drug Administration 2005a,b). Crops exceeding those thresholds are rejected from the market, which causes severe economic losses for farmers, processors, and traders (Bui-Klimke et al. 2014; Wu 2015).

Genetic diversity within Aspergillus spp. is vast. Species can be subdivided into vegetative compatibility groups (VCGs). VCGs are genetically isolated subpopulations delimited by a self/nonselfrecognition system that restricts gene flow between individuals having dissimilar alleles at loci governing vegetative incompatibility (Papa 1986). Significant variation in aflatoxin-producing potentials among VCGs exists, particularly within A. flavus (Cotty 1997; Cotty et al. 1994; Doster et al. 1996; Horn et al. 2000). Members of certain A. flavus VCGs do not produce aflatoxins due to defects in the aflatoxin biosynthesis gene cluster. Those individuals are referred to as atoxigenic. Certain VCGs are composed exclusively of atoxigenic members (Chang et al. 2005; Ehrlich and Cotty 2004; Grubisha and Cotty 2015). In species other than A. flavus, variability in aflatoxinproducing potential is less pronounced (Chang et al. 1995; Horn et al. 2000; Nesci and Etcheverry 2002).

In California, over the last decade, there has been an increase in unacceptable aflatoxin levels in pistachio, almond, and fig (Donner et al. 2015; Doster et al. 1996, 2014; Picot et al. 2017). This has resulted in rejection of tree crop lots, preventing entry into European markets (Bui-Klimke et al. 2014; RASFF 2017). Hot and dry conditions are associated with increases in aflatoxin contamination (Cotty et al. 1994), and those conditions are common in California (Herring et al. 2014; Liu et al. 2018) during the cropping season (March to September). In addition, in some years, allocation of irrigation water is restricted due to severe drought, and growers of nut crops and fig fruit implement reduced deficit irrigation tactics.

Aflatoxin preventive measures used by tree crop industries include good agricultural practices, navel orangeworm (Amyelois transitella) control, and sorting of defective, stained, and decayed fruit 
(Campbell et al. 2003; Higbee and Siegel 2012; Palumbo et al. 2014). However, these measures are often insufficient to produce crops with safe aflatoxin levels. A commercially acceptable technology to reduce aflatoxins in crops is the use of atoxigenic A. flavus strains during crop development to competitively displace naturally occurring aflatoxin-producing strains (Cotty 2006; Dorner 2004; Doster et al. 2014). As a direct consequence of the application of atoxigenic strains, treated crops become associated with the atoxigenic fungi and significantly less aflatoxins are produced. In 2003, Aspergillus flavus AF36, developed by the United States Department of AgricultureAgricultural Research Service (USDA-ARS), was the first biocontrol product to receive unrestricted registration by the United States Environmental Protection Agency (USEPA) to mitigate aflatoxin contamination of cottonseed (Cotty 2006; USEPA 2003). The active ingredient, A. flavus isolate AF36, was initially isolated in Arizona (Cotty 1989) and belongs to VCG YV36 (Ehrlich and Cotty 2004). VCG YV36 is the most frequently encountered atoxigenic VCG in Californian pistachio, almond, and fig orchards (Doster et al. 2007, 2014; Picot et al. 2018). AF36 has been registered now for use in all of these perennial crops (Doster et al. 2014; USEPA 2012, 2017). It took approximately 10 years of research with AF36 in pistachio orchards to obtain unrestricted registration for pistachio (USEPA 2012) and approximately five more years of research for similar registrations for almond and fig. Justification based on knowledge from use on pistachio and other crops was required to bridge the registration to an unrestricted registration from USEPA for use in almond and fig (USEPA 2017).

A second generation of aflatoxin biocontrol products employing mixtures of diverse atoxigenic A. flavus strains has been developed for use in African nations and the United States (Bandyopadhyay et al. 2016; Shenge et al. 2017). Genotypes belonging to VCGs well adapted to cropping systems in target areas are selected as activeingredient fungi (Atehnkeng et al. 2016; Mehl et al. 2012). Atoxigenic strain mixtures varying in adaptive traits to crops, soils, and microclimates may be more effective at establishing long-term atoxigenic Aspergillus communities (Atehnkeng et al. 2014; Mehl et al. 2012; Probst et al. 2011). Use of AF36 in pistachio orchards results in aflatoxin reductions significantly below those obtained in cottonseed and maize treated with AF36 (Doster et al. 2014). Using mixtures of atoxigenic genotypes rather than a single genotype (e.g., AF36) in tree crops could result in greater aflatoxin reductions because of greater long-term reductions in the aflatoxin-producing potential of associated A. flavus communities.

Table 1. Origin and substrate in which Aspergillus flavus isolates were collected and used in the current study

\begin{tabular}{|c|c|c|c|}
\hline \multirow[b]{2}{*}{ County } & \multicolumn{3}{|c|}{ Isolates evaluated $(n)^{\mathbf{y}}$} \\
\hline & Almond & Fig & Pistachio \\
\hline Butte & 76 & - & - \\
\hline Colusa & 34 & - & - \\
\hline Fresno & - & 8 & 17 \\
\hline Glenn & 63 & - & - \\
\hline Kern & 83 & - & 47 \\
\hline Kings & - & - & 17 \\
\hline Madera & 104 & 17 & 136 \\
\hline Merced & - & - & 12 \\
\hline Tulare & - & - & 60 \\
\hline Fresno/Madera ${ }^{\mathrm{z}}$ & - & 15 & - \\
\hline Total & 360 & 40 & 289 \\
\hline
\end{tabular}

${ }^{y}$ All A. flavus associated with almond were recovered from almond orchard soils and were previously classified as atoxigenic based in earlier studies (Donner et al. 2015; Picot et al. 2018). Isolates from fig and pistachio agroecosystems belong to the fungal collection of our laboratory and were not previously screened for aflatoxin-producing potential; - indicates that isolates from those counties were not available (the crops are either not grown on those counties or the fungal collection does not contain isolates originating from those counties).

${ }^{\mathrm{z}}$ The origin of 15 isolates recovered from Calimyrna fig fruit is from both of these counties. However, these were grown either in Fresno or Madera counties.
Fifteen frequent atoxigenic A. flavus VCGs originating from almond, fig, and pistachio orchards in California were previously identified using microsatellite analysis, with the ultimate aim of identifying active ingredients for biocontrol mixtures (Picot et al. 2018). The current study sought to extend previous work (Picot et al. 2018) by (i) characterizing membership in the 15 genetic VCGs common on almond, fig, and pistachio grown in California and (ii) testing the VCG abilities to reduce aflatoxin content in almond and pistachio kernels during co-infection with aflatoxin-producing A. flavus and A. parasiticus isolates. This additional information on fungal germplasm well adapted to tree crops, with superior ability to reduce aflatoxin content, is a resource for development of biocontrol products to treat almond, fig, and pistachio crops in California. A multi-strain biocontrol product directed at multiple crops may facilitate a true area-wide and environmentally safe aflatoxin management strategy for the benefit of highly profitable, aflatoxin-prone tree crops in California.

\section{Materials and Methods}

Atoxigenic A. flavus associated with almond. In total, 360 atoxigenic $A$. flavus isolates associated with almond soils sampled from 2007 to 2011 were part of a previous study (Table 1) (Picot et al. 2018) in which 15 dominant atoxigenic genetic groups (labeled $\mathrm{H} 1$ to H15) were delineated by microsatellite analyses (Grubisha and Cotty 2009). In the current study, these isolates were subjected to further characterization

Fungi associated with pistachio and fig. Isolates of $A$. flavus associated with pistachio $(n=289)$ and fig $(n=40)$ recovered from 1982 to 2007 from diverse research projects in our laboratory were used in the current study (Table 1). These isolates are maintained in the culture collection at Kearney Agricultural Research and Extension Center in Parlier, CA. None of these pistachio and fig isolates were part of our previous study (Picot et al. 2018). The aflatoxinproducing potential of the isolates was unknown, and it was expected that the populations were composed of both toxigenic and atoxigenic strains. Pistachio isolates were recovered from soils $(52.6 \%)$, leaf washes $(33.2 \%)$, nuts $(9.7 \%)$, and male inflorescences $(4.5 \%)$. Fig isolates were recovered from fruit $(52.5 \%)$ and soils $(47.5 \%)$.

Vegetative compatibility analyses. Nitrate-nonutilizing (nit) mutants of all A. flavus isolates from almond, pistachio, and fig $(n=360$, 289 , and 40 , respectively) were generated using previously described methodology (Ortega-Beltran and Cotty 2018). Briefly, nit mutants were selected on SEL agar (Czapek-Dox broth, $25 \mathrm{~g}$ of $\mathrm{KClO}_{3}$, $50 \mathrm{mg}$ of rose Bengal, and $2 \%$ Bacto-agar [Difco Laboratories Inc., Detroit, MI] per liter, pH 7.0) by seeding spore suspensions (approximately 1,000 spores in $15 \mu \mathrm{l}$ ) into $3-\mathrm{mm}$ central wells cut into agar. Plates were incubated at $31^{\circ} \mathrm{C}$ for up to 1 month. Spontaneous auxotrophic sectors were transferred onto MIT agar (Czapek-Dox broth, $15 \mathrm{~g}$ of $\mathrm{KClO}_{3}$, and $2 \%$ Bacto-agar per liter, $\mathrm{pH}$ 6.5), and incubated for 3 days at $31^{\circ} \mathrm{C}$ to further purify mutants. Mutants were then grown on 5-2 agar (5\% V8 juice [Campbell Soup Company, Camden, $\mathrm{NJ}$ ] and $2 \%$ Bacto-agar, $\mathrm{pH}$ 6.0) for 7 days at $31^{\circ} \mathrm{C}$. Mutants were saved as agar plugs of sporulating cultures in $8-\mathrm{ml}$ vials containing $4 \mathrm{ml}$ of sterile distilled water until used in vegetative compatibility analyses (VCA).

Complementary mutant tester pairs from 9 of the 15 atoxigenic genetic groups were developed using previously described methodologies (Ortega-Beltran and Cotty 2018). Tester pairs were also developed for two isolates not belonging to one of the 15 groups. Briefly, tester pairs were developed by pairing of niaD mutants with either a cnx or nirA $A^{-}$mutant on starch agar (36 $\mathrm{g}$ of dextrose, $20 \mathrm{~g}$ of soluble starch, $3 \mathrm{~g}$ of $\mathrm{NaNO}_{3}$, and $2 \%$ Bacto-agar per liter, $\mathrm{pH}$ 6.0). Complementary pairs were used to define individual VCGs. The tester pair of VCG YV36 (H14 in study by Picot et al. [2018]), ATCC 96045 and ATCC 96047, was developed over 20 years ago (Cotty 1994). All mutants of isolates were subjected to VCA with tester pairs of the 12 VCGs mentioned above, as previously described (Ortega-Beltran and Cotty 2018). Isolates yielding complementary mutants to a tester pair were placed in the corresponding VCG.

Influence of atoxigenic VCGs on aflatoxin contamination of both almond and pistachio kernels co-inoculated in 
the laboratory. Ability of identified atoxigenic VCGs to limit aflatoxin accumulation in almond and pistachio kernels was evaluated when independently co-inoculated with highly toxigenic isolates of either A. flavus (isolate 2A1L-11) or A parasiticus (isolate 4C1P11). Twelve VCGs were evaluated on almond and eight of those were also evaluated on pistachio. The toxigenic isolates were selected because of their production of large aflatoxin quantities in both chemically defined media and on viable almond kernels (A. Picot and T. J. Michailides, unpublished results).

For inoculum preparation, all fungal isolates were grown on 5-2 agar for 7 days $\left(31^{\circ} \mathrm{C}\right)$. Spores were collected with sterile cotton swabs, suspended in sterile distilled deionized water, quantified using a hemocytometer, and diluted to a concentration of $1.75 \times 10^{6}$ spores/ $\mathrm{ml}$. Sterile glass vials $(20 \mathrm{ml})$ contained approximately $5 \mathrm{~g}$ of mature, viable, and healthy kernels previously surface sterilized by submersion in hot water $\left(80^{\circ} \mathrm{C}\right.$ for $\left.45 \mathrm{~s}\right)$. Both almond and pistachio kernels were either co-inoculated with an aflatoxin-producer and an atoxigenic isolate (1:1; inoculated simultaneously) or with an aflatoxin-producer alone. Initial kernel moisture was 4 to $6 \%$. Spore suspensions containing approximately 350,000 spores/g of kernels were combined with appropriate amounts of sterile distilled water to bring kernel moisture to $25 \%$. This created a favorable environment for fungal growth. Adjusted suspensions were vortexed and distributed evenly on the surface of kernels. Kernels inoculated with sterile water served as a nontreated control. After inoculation, vials were covered with sterile plastic caps that allowed gas exchange and positioned in plastic containers (crispers; 32 by 23 by $10 \mathrm{~cm}$ ) into a randomized complete design and incubated for 7 days $\left(31^{\circ} \mathrm{C}\right)$. Treatments consisted of four replicates and each replicate consisted of a single kernel-containing glass vial. Each experiment was repeated twice.

For almond, competition experiments were terminated by adding $30 \mathrm{ml}$ of $60 \%$ methanol. Aflatoxins were extracted following the Association of Official Agricultural Chemists method (Kamimura et al. 1985), with minor modifications. Briefly, each almond-fungalmethanol mixture was transferred to a $110-\mathrm{ml}$ stainless steel laboratory blending jar (MC-2; Waring Commercial, Torrington, CT). Mixtures were combined with $1 \mathrm{~g}$ of $\mathrm{NaCl}$ and blended for $1 \mathrm{~min}$. Extracts were passed through fluted filter paper (number 1289; Vicam Inc., Watertown, MA), combined with $10 \mathrm{ml}$ of sterile water, and passed through a glass microfiber filter paper (number 691; VWR, Radnor, PA). From the second filtrate, a homogeneous 100- $\mu$ l aliquot was combined with $9.9 \mathrm{ml}$ of water and the suspension was eluted in an AflaTest immunoaffinity column (Vicam Inc.) at a rate of 2 drops/s. Two rinses of $10 \mathrm{ml}$ of water were conducted until air came through columns. Aflatoxins were eluted into glass vials passing $1 \mathrm{ml}$ of high-performance liquid chromatography (HPLC)grade methanol through the columns at a rate of 1 drop/s. Water $(1 \mathrm{ml})$ was added to each vial. Vials were stored at $-20^{\circ} \mathrm{C}$ before HPLC analyses. Aflatoxins were quantified using an HPLC Hewlett Packard 1050, as previously described (Doster et al. 1996).

For pistachio, competition experiments were terminated by adding $50 \mathrm{ml}$ of $70 \%$ methanol and mixtures were blended for $1 \mathrm{~min}$ (Conair Corporation, East Windsor, NJ) (Camiletti et al. 2018). Volumes of $1.5 \mathrm{ml}$ of filtered mixtures were transferred to 2-ml glass vials and evaporated at room temperature. The dry residue of each tube was dissolved in an appropriate volume of $70 \%$ methanol (Camiletti et al. 2018). Extracts $(4 \mu \mathrm{l})$ were spotted directly onto thin-layer chromatography (TLC) plates (Silica gel 60; Merck, Darmstadt, Germany) using a micropipette. Plates were developed in chloroformacetone (88:12) for $40 \mathrm{~min}$ and air dried. Aflatoxins were quantified using a CAMAG TLC Scanner 3 (Muttenz, Basle, Switzerland) with winCATS 1.4.2 software (Probst et al. 2011). Standards curves were calculated with different concentrations of aflatoxins $B_{1}, B_{2}, G_{1}$, and $\mathrm{G}_{2}$ purchased from Sigma-Aldrich (St. Louis, MO).

Statistical analyses. Aflatoxin $\mathrm{B}_{1}$ concentrations were logtransformed $\left[y=\log _{10}(1+\right.$ aflatoxin concentration in $\left.\mu \mathrm{g} / \mathrm{kg})\right]$ to normalize variances. Experiments were performed with completely randomized designs, and resulting data were subjected to analysis of variance. Means were separated with Tukey's honestly significant difference test $(\alpha=0.05)$. Aflatoxin reductions by atoxigenic isolates were calculated as ([1 - aflatoxin content in kernels coinoculated with an aflatoxin producer and an atoxigenic isolate]/[aflatoxin content in kernels inoculated with the aflatoxin producer alone] $) \times 100$, as described by Probst et al. (2011). The Satterthwaite for unequal variances $t$-test (Snedecor and Cochran 1980) was used to compare performances of each atoxigenic isolate in reducing aflatoxin $\mathrm{B}_{1}$ produced by $A$. flavus and A. parasiticus and aflatoxin $\mathrm{G}_{1}$ produced by A. parasiticus. All statistical tests were performed using Statistix 10 Analytical Software (Tallahassee, FL).

\section{Results}

Tester pairs of A. flavus VCGs. In a previous study (Picot et al. 2018), 15 groups of atoxigenic isolates were reported as candidate biocontrol genotypes based on their association with almond, pistachio, and fig grown in California. Some of the 15 groups belong to VCGs previously characterized jointly by our laboratory and USDA-ARS (unpublished results). VCGs CAM, CAS, CAC, CAG, CAP, and YV36 correspond to groups H2, H3, H6, H9, H13, and H14, respectively (Picot et al. 2018). In the current study, we developed tester pairs for the first time for groups $\mathrm{H} 1, \mathrm{H} 5, \mathrm{H}$, $\mathrm{H} 8, \mathrm{H} 10$, and $\mathrm{H} 15$, and for isolates 26B1L-11 and 15B2-08, which do not belong to any of the 15 groups described as dominant but were part of other studies in our laboratory. Tester pairs of groups H4, $\mathrm{H} 11$, and $\mathrm{H} 12$ were not developed due to their low frequencies. In addition, frequencies of VCGs CAC and CAS were not monitored in the current study because of their relatively low frequencies in the previous study (Picot et al. 2018). VCGs of H1, H5, H7, H8, $\mathrm{H} 10$, and H15, and for isolates 15B2-08 and 26B1L-11 were designated as CA012, CA004, CA007, CA001, CA003, CA010, CA008, and CA009, respectively. VCA were conducted with tester pairs of CAG, CAM, CAP, CA001, CA003, CA004, CA007, CA008, CA009, CA010, CA012, and YV36 for all mutants of the 689 isolates associated with almond, pistachio, and fig (Table 1).

Frequencies of atoxigenic VCGs in almond, pistachio, and fig populations. All of the almond-associated isolates were confirmed to belong to the VCGs/groups previously reported (Picot et al. 2018), except for two isolates not assigned to H10 but complementing the tester pair of the VCG developed for that group, CA003. However, these two isolates (19C2L-11 and 11B1L-11) are adjacent to the H10 group in the unweighted pairgroup method with arithmetic means dendrogram (Picot et al. 2018). Briefly, for almondassociated isolates, each examined VCG was detected in at least two of the five examined counties. VCGs CAG and CA003 were detected in four counties (six and seven isolates, respectively), and YV36 was detected in each of the five examined counties (41 isolates) (Table 2). Fig-associated isolates belonged to five of the VCGs (membership range $=1$ to 3 ) (Table 2 ). Isolates associated with pistachio were assigned to seven of the VCGs (membership range $=2$ to 18); CA003, CA010, and YV36 were detected in five of six counties $(17,18$, and 13 isolates, respectively) (Table 2). None of the mutants of isolates complemented with more than one VCG tester pair.

Interference with aflatoxin contamination by atoxigenic A. flavus. For each crop, results from two independent tests were similar, allowing results to be combined. All evaluated atoxigenic A. flavus isolates had excellent efficacy to limit almond and pistachio aflatoxin contamination (Tables 3 and 4).

In almond kernels, significantly $(P<0.001)$ higher aflatoxin concentrations were detected in kernels inoculated with the toxigenic isolates alone compared with any of the co-inoculations. For tests with $A$. flavus $2 \mathrm{~A} 1 \mathrm{~L}-11$, reductions in aflatoxin $\mathrm{B}_{1}$ content ranged from 82.2 to $98.0 \%$. For $A$. parasiticus $4 \mathrm{C} 1 \mathrm{P}-11$ tests aflatoxin reductions ranged from 91.4 to $98.0 \%$ and from 88.4 to $97.9 \%$ for aflatoxins $B_{1}$ and $\mathrm{G}_{1}$, respectively. There were significant $(P<0.001)$ differences among atoxigenic isolates (Table 3). Members of CA001, CA003, CA004, CA007, CA008, CA009, CA010, and YV36 allowed significantly less production of aflatoxin $\mathrm{B}_{1}$ when challenged with $2 \mathrm{~A} 1 \mathrm{~L}-11$. On the other hand, almost all atoxigenic isolates had similar efficacy in reducing aflatoxin $\mathrm{B}_{1}$ produced by 4C1P-11, except for CAG and CA012 (Table 3). No significant $(P>0.05)$ differences in abilities to reduce aflatoxin $\mathrm{G}_{1}$ were detected 
among the co-inoculated atoxigenic isolates. Isolates of CA007 and CA009 had greater $(P<0.05)$ aflatoxin $\mathrm{B}_{1}$ reductions when challenged with $2 \mathrm{~A} 1 \mathrm{~L}-11$ in comparison with $4 \mathrm{C} 1 \mathrm{P}-11$ while isolates of CAG, CAM, CAP, and CA012 had greater $(P<0.05)$ aflatoxin $\mathrm{B}_{1}$ reductions when challenged with $4 \mathrm{C} 1 \mathrm{P}-11$ than with $2 \mathrm{~A} 1 \mathrm{~L}-11$ (Table 3).

When pistachio kernels were co-inoculated with atoxigenic and aflatoxin-producing $A$. flavus isolates, there were significant $(P<$ 0.05 ) aflatoxin $\mathrm{B}_{1}$ reductions ( 88.8 to $96.8 \%$ ) compared with kernels inoculated with the aflatoxin producer alone (Table 4). However, there were no significant $(P>0.05)$ differences among the eight atoxigenic isolates evaluated. Likewise, all evaluated isolates significantly $(P<0.05)$ reduced aflatoxins produced by $A$. parasiticus (4C1P-11). Reductions ranged from 59.1 to $92.3 \%$ and 64.3 to 94.6\% for aflatoxins $B_{1}$ and $G_{1}$, respectively. The isolates $15 B 2-08$ and AF36 had higher $(P<0.05)$ aflatoxin $\mathrm{B}_{1}$ reduction when challenged with the toxigenic $A$. flavus isolate in comparison with the toxigenic $A$. parasiticus isolate.

\section{Discussion}

There are many A. flavus isolates lacking the ability to produce aflatoxins; those are known as atoxigenic strains (Cotty 2006). Strains

Table 2. Frequencies of 12 atoxigenic Aspergillus flavus vegetative compatibility groups (VCGs) in fungal populations associated with almond, fig, and pistachio cultivated in California

\begin{tabular}{|c|c|c|c|c|c|c|c|c|c|c|c|c|}
\hline \multirow[b]{2}{*}{ Crop, county } & \multicolumn{12}{|c|}{$\mathrm{VCG}^{\mathbf{z}}$} \\
\hline & CA001 & CAG & CA003 & CA004 & CAM & CA007 & CA008 & CA009 & CA010 & CAP & CA012 & YV36 \\
\hline \multicolumn{13}{|l|}{ Almond } \\
\hline Butte & .. & 1 & 2 & .. & .. & 1 & 1 & .. & .. & 1 & 2 & 8 \\
\hline Colusa & 1 & 2 & 1 & .. & .. & .. & .. & .. & 2 & .. & .. & 6 \\
\hline Glenn & .. & .. & 1 & 2 & 4 & .. & .. & .. & 3 &.. & .. & 4 \\
\hline Kern & .. & 2 & .. & .. & .. & .. & .. & 3 & 3 & 2 & .. & 14 \\
\hline Madera & 2 & 1 & 3 & 1 & 3 & 2 & 2 & 1 & .. & 1 & 1 & 9 \\
\hline Percentage & 0.8 & 1.7 & 1.9 & 0.8 & 1.9 & 0.8 & 0.8 & 1.1 & 2.2 & 1.1 & 0.8 & 11.4 \\
\hline \multicolumn{13}{|l|}{ Fig } \\
\hline Fresno & .. & .. & .. & .. & .. & .. & .. & .. & .. & .. & .. & 1 \\
\hline Madera & .. & .. & 1 & .. & .. & .. & .. & .. & .. & .. & .. &.. \\
\hline Unknown & .. & .. & 2 & .. & 2 & .. & 1 & .. & .. & .. & .. & 1 \\
\hline Percentage & .. & .. & 7.5 & .. & 5.0 & .. & 2.5 & .. & .. & .. & .. & 5.0 \\
\hline \multicolumn{13}{|l|}{ Pistachio } \\
\hline Fresno & .. & .. & 1 & .. & .. & .. & .. & .. & 1 & .. & .. & 2 \\
\hline Kern & .. & .. & 3 & .. & .. &.. & 1 & 2 & 8 & .. & .. & 4 \\
\hline Kings & 3 & .. & .. & .. & .. &.. & .. & .. & 4 & .. & .. & 1 \\
\hline Madera & .. & .. & 8 & .. & .. &.. & 5 & 7 & 1 & .. & .. & 5 \\
\hline Merced & .. & .. & 1 & .. & .. &.. & .. & 1 & .. & .. & .. &.. \\
\hline Tulare &.. & .. & 4 &.. & .. & .. &.. & 2 & 4 & 2 &.. & 1 \\
\hline Percentage & 1.0 & .. & 5.9 & .. & .. & .. & 2.1 & 4.2 & 6.2 & 0.7 & .. & 4.5 \\
\hline
\end{tabular}

$\mathrm{z}$ Tester pairs of VCGs were developed for some of the dominant atoxigenic A. flavus groups reported in a previous study (Picot et al. 2018). Tester pairs of VCGs of some of the dominant groups (CAG, CAM, CAP, and YV36) were previously developed. The number of isolates tested for vegetative compatibility was 360, 289, and 40 for the almond, pistachio, and fig populations, respectively. Percentage of each VCG among the examined population is reported.

Table 3. Ability of isolates belonging to 12 atoxigenic Aspergillus flavus vegetative compatibility groups (VCGs) native to California to reduce aflatoxin accumulation in almond kernels when coinoculated with an aflatoxin-producing isolate of either A. flavus or A. parasiticus

\begin{tabular}{|c|c|c|c|c|c|c|c|}
\hline \multirow[b]{2}{*}{ Isolate $^{\mathrm{x}}$} & \multirow[b]{2}{*}{ VCG } & \multicolumn{2}{|c|}{ A. flavus $2 \mathrm{~A} 1 \mathrm{~L}-11^{\mathrm{w}}$} & \multicolumn{4}{|c|}{ A. parasiticus 4C1P-11 ${ }^{\mathrm{w}}$} \\
\hline & & Aflatoxin $B_{1}(\mu \mathrm{g} / g)^{y}$ & $\mathrm{~B}_{1}$ reduction $(\%)^{\mathrm{z}}$ & Aflatoxin $B_{1}(\mu g / g) y$ & $\mathrm{~B}_{1}$ reduction $(\%)^{\mathrm{z}}$ & Aflatoxin $G_{1}(\mu g / g)^{y}$ & $\mathrm{G}_{1}$ reduction $(\%)^{\mathrm{z}}$ \\
\hline None & $\ldots$ & $109.9 \mathrm{a}$ & & $183.4 \mathrm{a}$ & $\ldots$ & $19.3 \mathrm{a}$ & \\
\hline $5 \mathrm{C} 4 \mathrm{~L}-11$ & CA001 & $3.0 \mathrm{de}$ & $97.3 \pm 0.6$ & $3.9 \mathrm{bc}$ & $97.5 \pm 1.7$ & $0.6 \mathrm{~b}$ & $97.4 \pm 2.1$ \\
\hline 7C5L-10 & CAG & $20.1 \mathrm{~b}$ & $82.2 \pm 7.1^{*}$ & $12.8 \mathrm{~b}$ & $91.4 \pm 6.7$ & $2.6 \mathrm{~b}$ & $88.4 \pm 9.5$ \\
\hline $10 \mathrm{C} 4 \mathrm{~L}-10$ & CA003 & 5.4 cde & $95.2 \pm 2.3$ & $5.6 \mathrm{bc}$ & $96.4 \pm 2.3$ & $1.1 \mathrm{~b}$ & $94.9 \pm 4.1$ \\
\hline 15B3L-11 & CA004 & $4.6 \mathrm{de}$ & $95.9 \pm 3.5$ & $3.3 \mathrm{bc}$ & $98.0 \pm 0.8$ & $0.4 \mathrm{~b}$ & $97.9 \pm 1.0$ \\
\hline $13 \mathrm{~A} 3 \mathrm{~L} 10$ & CAM & $10.9 \mathrm{bcd}$ & $90.3 \pm 4.6$ & $3.6 \mathrm{bc}$ & $97.7 \pm 2.0$ & $0.6 \mathrm{~b}$ & $97.0 \pm 2.7$ \\
\hline $12 \mathrm{C} 4 \mathrm{~L}-11$ & CA007 & 5.9 bcde & $94.8 \pm 1.9^{*}$ & $11.8 \mathrm{~b}$ & $92.1 \pm 6.0$ & $2.1 \mathrm{~b}$ & $90.6 \pm 7.6$ \\
\hline 15B2-08 & CA008 & $2.2 \mathrm{e}$ & $98.0 \pm 1.7$ & $3.5 \mathrm{bc}$ & $97.8 \pm 1.5$ & $1.0 \mathrm{~b}$ & $95.7 \pm 4.5$ \\
\hline 26B1L-11 & CA009 & $4.4 \mathrm{e}$ & $96.1 \pm 3.6^{*}$ & $8.3 \mathrm{bc}$ & $94.4 \pm 5.0$ & $2.2 \mathrm{~b}$ & $90.3 \pm 9.2$ \\
\hline $3 \mathrm{~A} 2 \mathrm{~L}-11$ & CA010 & $4.3 \mathrm{de}$ & $96.2 \pm 2.2$ & $6.1 \mathrm{bc}$ & $96.3 \pm 3.4$ & $1.0 \mathrm{~b}$ & $95.5 \pm 4.2$ \\
\hline 20A10L-11 & CAP & $17.5 \mathrm{bc}$ & $84.5 \pm 7.6^{*}$ & $10.6 \mathrm{bc}$ & $93.2 \pm 5.0$ & $2.4 \mathrm{~b}$ & $89.3 \pm 8.9$ \\
\hline $17 \mathrm{C} 2 \mathrm{~L}-11$ & CA012 & $18.5 \mathrm{bc}$ & $83.7 \pm 8.0^{*}$ & $4.0 \mathrm{bc}$ & $97.2 \pm 2.4$ & $0.9 \mathrm{~b}$ & $96.1 \pm 3.6$ \\
\hline AF36 & YV36 & $2.4 \mathrm{e}$ & $97.9 \pm 0.9$ & $3.0 \mathrm{c}$ & $97.9 \pm 2.1$ & $1.2 \mathrm{~b}$ & $94.8 \pm 6.4$ \\
\hline
\end{tabular}

${ }^{\mathrm{w}}$ Toxigenic isolates, native to the California almond agroecosystem, were selected based on their ability to produce large aflatoxin quantities over several substrates (A. Picot and T. J. Michailides, unpublished).

$\mathrm{x}$ Toxigenic isolates were co-inoculated with atoxigenic isolates belonging to 12 atoxigenic VCGs. The first row indicates aflatoxin concentrations for almonds inoculated only with the corresponding toxigenic isolate alone.

y Aflatoxin values followed by same letters within a column do not differ significantly according to Tukey's honestly significant difference test $(P=0.05)$. The limit of detection for each aflatoxin was $0.3 \mathrm{ng} / \mathrm{g}$. Values with an asterisk $\left(^{*}\right)$ indicate significant differences in isolates' abilities to limit aflatoxin $\mathrm{B}_{1}$ produced by $2 \mathrm{~A} 1 \mathrm{~L}-11$ and $4 \mathrm{C} 1 \mathrm{P}-11$ according to the Satterthwaite test $(P=0.05)$.

z Percent aflatoxin reduction was calculated as (1 - [aflatoxin content in pistachio co-inoculated with both toxigenic and atoxigenic isolate/aflatoxin content in pistachio inoculated with a toxigenic isolate alone]) $\times 100$ (Probst et al. 2011). Two independent tests with similar results were combined for the analyses (total $n=8)$. $\mathrm{B}_{1}$ reductions were calculated independently for co-inoculations of pistachio kernels with A. flavus $2 \mathrm{~A} 1 \mathrm{~L}-11$ and $A$. parasiticus $4 \mathrm{C} 1 \mathrm{P}-11$. $\mathrm{G}_{1}$ reductions were calculated for co-inoculations of kernels with A. parasiticus 4C1P-11. 
of A. flavus VCGs composed exclusively of atoxigenic members can be employed as biocontrol agents to limit crop aflatoxin content (Mehl et al. 2012). Atoxigenic strains used in biocontrol formulations limit contamination by reducing frequencies of aflatoxin producers. Atoxigenic A. flavus also reduced aflatoxin contamination during co-infection of crops with aflatoxin producers. Use of atoxigenic strains in biocontrol formulations is the only commercially proven, consistent, and environmentally safe technology that allows production of an aflatoxin-safe crops. For application, atoxigenic strains are dispersed using a nutritive source (e.g., sterile wheat, barley, or sorghum grain carrier) that provides both reproductive and dispersal advantages over native Aspergillus fungi in the target environment. Applied strains reproduce on the grain carrier, spread, and colonize substrates in the field before other Aspergillus fungi, allowing the applied fungi to participate in founder effects and dominate the cropassociated fungal population (Ortega-Beltran and Cotty 2018). A single application, at the correct crop stage, protects the crop from toxigenic fungi before, during, and after harvest (Cotty et al. 2007; Dorner 2009). Treated crops usually attain safe aflatoxin concentrations and, in many cases, the levels are below the limit of detection (Cotty et al. 2007; Mehl et al. 2012; USEPA 2003, 2012). We examined frequencies of 12 atoxigenic A. flavus VCGs in populations associated with almond, pistachio, and fig grown in California. Members of three VCGs were detected in the three crops. Members of six VCGs were detected in two crops, either almond and fig or almond and pistachio. Three VCGs were detected only in almond, suggesting that some VCGs may have crop-specific associations in a manner similar to the association of certain VCGs of $A$. parasiticus with sugarcane (Garber and Cotty 2014). VCGs associated with multiple crops may be particularly valuable in California's mixed-crop production system.

Pistachio was the first perennial crop allowed by USEPA to be treated with the biocontrol product Aspergillus flavus AF36 (USEPA 2012). The active ingredient fungus of AF36 belongs to VCG YV36 (Ehrlich and Cotty 2004). Registration was granted based on natural occurrence of YV36 members in pistachio orchards and experimental efficacy data, and by bridging toxicological information and knowledge of the original AF36 dossier for use in cotton and the amendment for use in maize (Doster et al. 2014). In August 2017, USEPA granted registration for use of AF36 in almond and fig crops based on the frequent natural occurrence of YV36 members in almond and fig orchards (Doster et al. 2007; Picot et al. 2018) and the absence of risks to honeybees posed by use of atoxigenic fungi (Ortega-Beltran et al. 2018).
Almond, fig, and pistachio industries contribute substantially to California's economy. The almond industry annually generates over U.S.\$21 billion gross revenue (Sumner et al. 2014). Fruit of these crops were occasionally contaminated with aflatoxins (Doster and Michailides 1994; Doster et al. 1996; Palumbo et al. 2014). However, in the last decade, drier and hotter conditions (Herring et al. 2014; Liu et al. 2018) have led to increased fungal activity and subsequent aflatoxin production. High levels of navel orangeworm damage in the susceptible crops across the state has resulted in aflatoxin contamination more frequent than normal. Several Californian lots have been rejected from domestic and international premium markets because of high aflatoxin concentrations. More frequent, more severe aflatoxin outbreaks are expected to occur due to climatic change (Magan et al. 2011).

Pistachio treated with AF36 contains 20 to $45 \%$ less aflatoxins than nontreated pistachio (Doster et al. 2014). Even though use of AF36 allows pistachio industries to meet safe aflatoxin levels, reductions in pistachio are less than those obtained in cottonseed and maize treated with AF36 (>80\%). Experimental use of AF36 in both almond and fig resulted in similar aflatoxin reductions as in pistachio (Doster et al. 2007). Improving the knowledge of the biology of AF36 in tree orchards may aid in designing strategies to achieve greater sporulation capacity and long-term persistence to increase efficacy in reducing aflatoxin content in nut crops and fig (Doster et al. 2014). After applying AF36, the agent dominates Aspergillus communities in both treated and neighboring, nontreated fields. Applications in one cropping season have some carryover benefits in subsequent years (Cotty et al. 2007; Doster et al. 2014; Jaime et al. 2012). Gradual decline of dominant $A$. flavus genotypes is common in natural populations in both single fields and over large areas and, thus, it is expected to occur for atoxigenic strains used in biocontrol formulations (Ortega-Beltran and Cotty 2018). Using a multi-strain product can promote more stable atoxigenic Aspergillus communities and facilitate lower crop aflatoxin content (Atehnkeng et al. 2014; Bandyopadhyay et al. 2016; Cotty et al. 2007; Mehl et al. 2012; Probst et al. 2011). There is plenty of atoxigenic germplasm associated with susceptible tree crops in California from which to select to tailor a multistrain product to treat tree crops (Picot et al. 2018).

Our previous study revealed 15 atoxigenic groups, including YV36, dominating almond communities (Picot et al. 2018). Strains of 12 VCGs detected in either the previous or current study were subjected to additional tests. Several VCGs were associated with either two or three crops, at multiple locations, over multiple years

Table 4. Ability of isolates belonging to eight atoxigenic Aspergillus flavus vegetative compatibility groups (VCGs) native to California to reduce aflatoxin accumulation in pistachio kernels when coinoculated with an aflatoxin-producing isolate of either A. flavus or A. parasiticus

\begin{tabular}{|c|c|c|c|c|c|c|c|}
\hline \multirow[b]{2}{*}{ Isolate $^{x}$} & \multirow[b]{2}{*}{ VCG } & \multicolumn{2}{|c|}{ A. flavus $2 \mathrm{~A} 1 \mathrm{~L}-11^{\mathrm{w}}$} & \multicolumn{4}{|c|}{ A. parasiticus $4 \mathrm{C} 1 \mathrm{P}-11^{\mathrm{w}}$} \\
\hline & & Aflatoxin $B_{1}(\mu g / g)^{y}$ & $\mathrm{~B}_{1}$ reduction $(\%)^{\mathrm{z}}$ & Aflatoxin $B_{1}(\mu \mathrm{g} / g)^{y}$ & $\mathrm{~B}_{1}$ reduction $(\%)^{\mathrm{z}}$ & Aflatoxin $G_{1}(\mu \mathrm{g} / g)^{y}$ & $\mathbf{G}_{1}$ reduction $(\%)^{\mathbf{z}}$ \\
\hline None & $\ldots$ & $134.6 \mathrm{a}$ & $\ldots$ & $126.7 \mathrm{a}$ & $\ldots$ & $20.1 \mathrm{a}$ & $\ldots$ \\
\hline $5 \mathrm{C} 4 \mathrm{~L}-11$ & CA001 & $9.6 \mathrm{~b}$ & $92.8 \pm 5.9$ & $41.1 \mathrm{~b}$ & $64.3 \pm 10.2$ & $8.2 \mathrm{ab}$ & $59.1 \pm 16.3$ \\
\hline $10 \mathrm{C} 4 \mathrm{~L}-10$ & CA003 & $4.2 \mathrm{~b}$ & $96.9 \pm 2.0$ & $11.5 \mathrm{~b}$ & $90.9 \pm 8.4$ & $1.6 \mathrm{~b}$ & $91.6 \pm 6.8$ \\
\hline $12 \mathrm{C} 4 \mathrm{~L}-11$ & CA007 & $14.5 \mathrm{~b}$ & $89.2 \pm 8.1$ & $6.8 \mathrm{~b}$ & $94.6 \pm 3.5$ & $1.5 \mathrm{~b}$ & $92.3 \pm 6.5$ \\
\hline $15 \mathrm{~B} 2-08$ & CA008 & $3.5 \mathrm{~b}$ & $97.3 \pm 1.6^{*}$ & $14.1 \mathrm{~b}$ & $87.9 \pm 8.4$ & $2.4 \mathrm{~b}$ & $88.8 \pm 9.6$ \\
\hline 26B1L-11 & CA009 & $13.8 \mathrm{~b}$ & $89.7 \pm 3.2$ & $14.3 \mathrm{~b}$ & $88.6 \pm 1.1$ & $3.3 \mathrm{~b}$ & $83.6 \pm 8.7$ \\
\hline 3A2L-11 & CA010 & $7.1 \mathrm{~b}$ & $94.7 \pm 2.7$ & $11.8 \mathrm{~b}$ & $90.7 \pm 6.2$ & $2.4 \mathrm{~b}$ & $87.8 \pm 8.4$ \\
\hline $17 \mathrm{C} 2 \mathrm{~L}-11$ & CA012 & $3.7 \mathrm{~b}$ & $97.3 \pm 2.4$ & $6.8 \mathrm{~b}$ & $94.6 \pm 3.2$ & $1.4 \mathrm{~b}$ & $93.2 \pm 6.5$ \\
\hline AF36 & YV36 & $3.9 \mathrm{~b}$ & $97.4 \pm 1.9^{*}$ & $13.2 \mathrm{~b}$ & $89.5 \pm 6.4$ & $2.3 \mathrm{~b}$ & $87.9 \pm 7.5$ \\
\hline
\end{tabular}

${ }^{\mathrm{w}}$ Toxigenic isolates, native to the California almond agroecosystem, were selected based on their ability to produce large aflatoxin quantities over several substrates (A. Picot and T. J. Michailides, unpublished).

${ }^{x}$ Toxigenic isolates were co-inoculated with atoxigenic isolates belonging to eight atoxigenic VCGs. The first row indicates aflatoxin concentrations for pistachio inoculated only with the corresponding toxigenic isolate alone.

y Aflatoxin values followed by same letters within a column do not differ significantly according to Tukey's honestly significant difference test $(P=0.05)$. The limit of detection for each aflatoxin was $0.3 \mathrm{ng} / \mathrm{g}$. Values with an asterisk (*) indicate significant differences in isolates' abilities to limit aflatoxin $B_{1}$ produced by 2A1L-11 and 4C1P-11 according to the Satterthwaite test $(P=0.05)$.

${ }^{\mathrm{z}}$ Percent aflatoxin reduction was calculated as $(1-$ [aflatoxin content in pistachio co-inoculated with both toxigenic and atoxigenic isolate/aflatoxin content in pistachio inoculated with a toxigenic isolate alone]) $\times 100$ (Probst et al. 2011). Two independent tests with similar results were combined for the analyses (total $n=8)$. $\mathrm{B}_{1}$ reductions were calculated independently for co-inoculations of pistachio kernels with A. flavus $2 \mathrm{~A} 1 \mathrm{~L}-11$ and A. parasiticus $4 \mathrm{C} 1 \mathrm{P}-11$. $\mathrm{G}_{1}$ reductions were calculated for co-inoculations of kernels with A. parasiticus 4C1P-11. 
(Table 2). Adaptation of A. flavus VCGs to multiple ecological niches is well known (Cotty and Mellon 2006; Mehl and Cotty 2010). VCGs CA003, CA008, and YV36 were found in almond, pistachio, and fig populations (range $=0.6$ to $10.8 \%$ ) (Table 2). Because communities of pistachio and fig were composed of both toxigenic and atoxigenic fungi, those percentages would have been higher if only atoxigenic fungi were evaluated, as in the almond population. Our results suggest that several VCGs reported here possess competitive advantages over other VCGs. YV36 continues to be identified as a dominant genotype associated with the three crops: 4.5, 5.0, and $11.4 \%$ of pistachio, fig, and almond populations, respectively. High frequencies of an atoxigenic VCG across a target area is a major criterion for use as a biocontrol agent (Atehnkeng et al. 2016; Cotty 2006; Mauro et al. 2013; Mehl et al. 2012; Probst et al. 2011). VCGs occurring at high frequencies in orchards of either two or three crops could supplement the efficacy of AF36 in limiting aflatoxin accumulation, if they are used in mixtures with AF36.

Another important criterion to select strains as biocontrol agents is their competitive ability to limit aflatoxin content during co-infection with aflatoxin producers (Atehnkeng et al. 2008; Cotty et al. 2007; Mauro et al. 2015; Probst et al. 2011). All tested atoxigenic strains significantly $(P<0.001)$ reduced aflatoxin content but there were differences among strains (Tables 3 and 4$)$. Some isolates differed $(P<$ $0.05)$ in their ability to reduce aflatoxins produced by A. flavus and A. parasiticus (Table 3). For example, in almond, isolates of CAG, CAM, CAP, and CA012 were more efficient against $A$. parasiticus. A strain of one of those VCGs may increase the efficacy of a biocontrol mixture, especially in Northern California, where A. parasiticus thrives (Donner et al. 2015).

Infection by aflatoxin-producing fungi on tree crops is complex and becomes even more complicated by involvement of navel orangeworm, which attacks almond, fig, and pistachio. Most fungal propagules arrive from sources not originating from the same orchard (Doster et al. 2014). When AF36 is applied in orchard soils, relatively low AF36 frequencies reach the height where tree nuts and fig fruit are located. It may take several cropping seasons to develop stable atoxigenic communities if susceptible crops planted nearby are not treated in a similar manner. Treating the three tree crops with a mixture of atoxigenic strains well adapted to them will result in a true area-wide aflatoxin reduction strategy that will positively impact health and food sectors in California and will potentially benefit other crops (e.g., walnut and pecan). Although effective navel orangeworm management is still very critical in these tree crops, AF36 and other atoxigenic strains that may be used are valuable tools to reduce frequencies of harmful toxigenic Aspergillus strains and the aflatoxins they produce.

More research is needed to (i) improve efficacy, and determine application timing and use of supplementary doses (Atehnkeng et al. 2014; Cotty et al. 2007; Jaime et al. 2017; Mehl et al. 2012); (ii) determine whether multiple strains should be applied in synchrony or progressively (Doster et al. 2014), (iii) determine whether strains in a biocontrol mixture should be manufactured collectively as currently done (Bandyopadhyay et al. 2016) or individually (Shenge et al. 2017); and (iv) assess influences of soil types on atoxigenic strain survival (Antilla and Cotty 2004). Alkaline soils predominate in agricultural areas of California and sensitivity to soil alkalinity among isolates belonging to the examined VCGs exists (OrtegaBeltran et al. 2015). Mechanisms for alkalinity tolerance in atoxigenic $A$. flavus should be further investigated.

It may take decades to develop commercially acceptable cultivars of almond, fig, and pistachio with features allowing less fungal infection and aflatoxin contamination (e.g., possessing anatomical barriers to infection). As an example, resistance to aflatoxin contamination of maize has been sought for almost 40 years but there are no commercially acceptable resistant cultivars available (Warburton and Williams 2014). Therefore, biocontrol of aflatoxins remains as the only practical solution to decrease aflatoxin content. Even though somewhat effective aflatoxin management tools are available for use by tree crop farmers in California, both climatic change and market pressures demand improved aflatoxin biocontrol technologies.
Use of a biocontrol product composed of a mixture of atoxigenic strains is a proven tool to limit aflatoxin contamination of crops (Atehnkeng et al. 2014; Mehl et al. 2012; Probst et al. 2011) and tree crop industries in California would benefit if a mixture of native, superior atoxigenic strains is registered for their use. However, registration of biocontrol agents with USEPA can take considerable time. Registration of AF36 with USEPA took well over a decade because it was a new technology and extensive ecological and toxicological data requirements needed to be satisfied (Cotty et al. 2007; USEPA 2012). An approval system accepting efficacy, ecological, and toxicological data of previous products is needed to fast-track the registration process. Atoxigenicity occurs due to natural defects in one or more genes in the aflatoxin biosynthetic gene cluster (Ehrlich and Cotty 2004; Yu et al. 2004) and those genetic defects, including in AF36, have been maintained over evolutionary time and are not susceptible to reversion (Adhikari et al. 2016). Thus, all atoxigenic isolates reported in the current study should be considered stable and safe for use as biocontrol agents. Some of the atoxigenic isolates reported in the current study were isolated from samples collected as early as in 1982, well before the concept of aflatoxin biocontrol was developed (Cotty 1989).

All of the atoxigenic VCGs reported in the current study are relevant genetic resources for use in a multi-crop, multi-strain aflatoxin biocontrol program in susceptible crops across California. The atoxigenic VCGs evaluated in the current study represent only a fragment of the atoxigenic A. flavus population resident in California nut and fig orchards. Atoxigenic VCGs not detected during the course of the current study may also be valuable for future use in aflatoxin biocontrol programs. Results of the current study build upon our previous studies (Donner et al. 2015; Picot et al. 2018) toward providing additional support to register the first mixture of atoxigenic strains well adapted to perennial crops to be used in vast areas of California to overcome current and future aflatoxin-related challenges that almond, fig, and pistachio industries suffer from in some years.

\section{Acknowledgments}

We thank L. Boeckler and M. Luna for their technical assistance.

\section{Literature Cited}

Adhikari, B. N., Bandyopadhyay, R., and Cotty, P. J. 2016. Degeneration of aflatoxin gene clusters in Aspergillus flavus from Africa and North America. AMB Express 6:62.

Amaike, S., and Keller, N. P. 2011. Aspergillus flavus. Annu. Rev. Phytopathol 49:107-133.

Antilla, L., and Cotty, P. J. 2004. Refinements in atoxigenic strain production, distribution, and application for suppression of aflatoxin-producing fungi in Arizona cotton. Pages 82-83 in: Proc. 4th Fungal Genomics, 5th Fumonisin Elimination, and 17th Aflatoxin Elimination Workshops. Agricultural Research Service, Beltsville, MD and Sacramento, CA

Atehnkeng, J., Donner, M., Ojiambo, P. S., Ikotun, B., Augusto, J., Cotty, P. J., and Bandyopadhyay, R. 2016. Environmental distribution and genetic diversity of vegetative compatibility groups determine biocontrol strategies to mitigate aflatoxin contamination of maize by Aspergillus flavus. Microb. Biotechnol. 9:75-88.

Atehnkeng, J., Ojiambo, P. S., Cotty, P. J., and Bandyopadhyay, R. 2014. Field efficacy of a mixture of atoxigenic Aspergillus flavus Link: Fr vegetative compatibility groups in preventing aflatoxin contamination in maize (Zea mays L.). Biol. Control 72:62-70.

Atehnkeng, J., Ojiambo, P. S., Ikotun, T., Sikora, R. A., Cotty, P. J., and Bandyopadhyay, R. 2008. Evaluation of atoxigenic isolates of Aspergillus flavus as potential biocontrol agents for aflatoxin in maize. Food Addit. Contam. 25:1264-1271.

Bandyopadhyay, R., Ortega-Beltran, A., Akande, A., Mutegi, C., Atehnkeng, J., Kaptoge, L., Senghor, A. L., Adhikari, B. N., and Cotty, P. J. 2016. Biological control of aflatoxins in Africa: Current status and potential challenges in the face of climate change. World Mycotoxin J. 9:771-789.

Bui-Klimke, T. R., Guclu, H., Kensler, T. W., Yuan, J.-M., and Wu, F. 2014 Aflatoxin regulations and global pistachio trade: Insights from social network analysis. PLoS One 9:e92149.

Camiletti, B. X., Moral, J., Asensio, C. M., Torrico, A. K., Lucini, E. I., GiménezPecci, M., and Michailides, T. J. 2018. Characterization of Argentinian endemic Aspergillus flavus isolates and their potential use as biocontrol agents for mycotoxins in maize. Phytopathology 108:818-828.

Campbell, B. C., Molyneux, R. J., and Schatzki, T. F. 2003. Current research on reducing pre- and post-harvest aflatoxin contamination of U.S. almond, pistachio and walnut. Toxin Rev. 22:225-266. 
CAST. 2003. Mycotoxins: Risks in Plant, Animal and Human Systems. Rep. No. 139. Council for Agricultural Science and Technology, Ames, IA.

Chang, P.-K., Cary, J. W., Yu, J., Bhatnagar, D., and Cleveland, T. E. 1995. The Aspergillus parasiticus polyketide synthase gene $p k s A$, a homolog of Aspergillus nidulans $w A$, is required for aflatoxin $\mathrm{B}_{1}$ biosynthesis. Mol. Gen. Genet. 248:270-277.

Chang, P.-K., Horn, B. W., and Dorner, J. W. 2005. Sequence breakpoints in the aflatoxin biosynthesis gene cluster and flanking regions in nonaflatoxigenic Aspergillus flavus isolates. Fungal Genet. Biol. 42:914-923.

Cotty, P. J. 1989. Virulence and cultural characteristics of two Aspergillus flavus strains pathogenic on cotton. Phytopathology 79:808-814.

Cotty, P. J. 1994. Influence of field application of an atoxigenic strain of Aspergillus flavus on the populations of A. flavus infecting cotton balls and on the aflatoxin content of cottonseed. Phytopathology 84:1270-1277.

Cotty, P. J. 1997. Aflatoxin-producing potential of communities of Aspergillus section Flavi from cotton producing areas in the United States. Mycol. Res. 101:698-704.

Cotty, P. J. 2006. Biocompetitive exclusion of toxigenic fungi. Pages 179-197 in: The Mycotoxin Factbook. D. Barug, D. Bhatnagar, H. P. van Egdmond, J. W. van der Kamp, W. A. van Osenbruggen, and A. Visconti, eds. Academic Publishers, Wageningen, The Netherlands.

Cotty, P. J., Antilla, L., and Wakelyn, P. J. 2007. Competitive exclusion of aflatoxin producers: Farmer driven research and development. Pages 241-253 in: Biological Control: A Global Perspective. C. Vincent, N. Goettel, and G. Lazarovits, eds. CAB International, Oxfordshire, UK.

Cotty, P. J., Bayman, P., Egel, D. S., and Elias, K. S. 1994. Agriculture, aflatoxins and Aspergillus. Pages 1-27 in: The Genus Aspergillus. K. Powell, ed. Plenum Press, New York.

Cotty, P. J., and Mellon, J. E. 2006. Ecology of aflatoxin-producing fungi and biocontrol of aflatoxin contamination. Mycotoxin Res. 22:110-117.

Donner, M., Lichtemberg, P. S. F., Doster, M., Picot, A., Cotty, P. J., Puckett, R. D., and Michailides, T. J. 2015. Community structure of Aspergillus flavus and A. parasiticus in major almond-producing areas of California, United States. Plant Dis. 99:1161-1169.

Dorner, J. W. 2004. Biological control of aflatoxin contamination of crops. J. Toxicol. Toxin Rev. 23:425-450.

Dorner, J. W. 2009. Biological control of aflatoxin contamination in corn using a nontoxigenic strain of Aspergillus flavus. J. Food Prot. 72:801-804.

Doster, M., Michailides, T. J., Cotty, P. J., Felts, D., Eveillard, H., Charbaut, T., Boeckler, L., Morgan, D. P., Reyes, H., and Windh, J. 2007. Aflatoxin control in figs and almonds: Biocontrol using the atoxigenic strain AF36. Pages 56-57 in: 2007 Annu. Multi-crop Aflatoxin/Fumonisin Elimination Fungal Genomics Workshop. Agricultural Research Service, Beltsville, MD and Atlanta, GA

Doster, M. A., Cotty, P. J., and Michailides, T. J. 2014. Evaluation of the atoxigenic Aspergillus flavus strain AF36 in pistachio orchards. Plant Dis. 98:948-956.

Doster, M. A., and Michailides, T. J. 1994. Aspergillus molds and aflatoxins in pistachio nuts in California. Phytopathology 84:583-590.

Doster, M. A., Michailides, T. J., and Morgan, D. P. 1996. Aspergillus species and mycotoxins in figs from California orchards. Plant Dis. 80:484-489.

Ehrlich, K. C., and Cotty, P. J. 2004. An isolate of Aspergillus flavus used to reduce aflatoxin contamination in cottonseed has a defective polyketide synthase gene. Appl. Microbiol. Biotechnol. 65:473-478.

Food and Drug Administration. 2005a. Manual of Compliance Policy Guides (Sec. 555.400 Foods-Adulteration with Aflatoxin). Office of Regulatory Affairs, Washington, DC.

Food and Drug Administration. 2005b. Manual of Compliance Policy Guides (Sec. 570.500 Pistachio Nuts-Aflatoxin Adulteration). Office of Regulatory Affairs, Washington, DC.

Garber, N. P., and Cotty, P. J. 2014. Aspergillus parasiticus communities associated with sugarcane in the Rio Grande Valley of Texas: Implications of global transport and host association within Aspergillus section Flavi. Phytopathology 104:462-471.

Grubisha, L. C., and Cotty, P. J. 2009. Twenty-four microsatellite markers for the aflatoxin-producing fungus Aspergillus flavus. Mol. Ecol. Resour. 9: 264-267.

Grubisha, L. C., and Cotty, P. J. 2015. Genetic analysis of the Aspergillus flavus vegetative compatibility group to which a biological control agent that limits aflatoxin contamination in USA crops belongs. Appl. Environ. Microbiol. 81: 5889-5899.

Herring, S. C., Hoerling, M. P., Peterson, T. C., and Stott, P. A. 2014. Explaining extreme events of 2013 from a climate change perspective. Bull. Am. Meteorol. Soc. 95:S1-S96.

Higbee, B. S., and Siegel, J. P. 2012. Field efficacy and application timing of methoxyfenozide, a reduced risk treatment for control of navel orangeworm (Lepidoptera: Pyralidae) in almond. J. Econ. Entomol. 105:1702-1711.

Horn, B. W., Greene, R. L., and Dorner, J. W. 2000. Inhibition of aflatoxin $\mathrm{B}_{1}$ production by Aspergillus parasiticus using nonaflatoxigenic strains: Role of vegetative compatibility. Biol. Control 17:147-154.

IARC. 2002. Monographs on the evaluation of carcinogenic risks to humans: Some traditional herbal medicines, some mycotoxins, naphthalene and styrene. Summary of data reported and evaluation, Vol. 82.
Jaime, R., Antilla, L., Liesner, L., and Cotty, P. J. 2017. Options to reduce costs of aflatoxin control in commercial cotton with area-wide programs utilizing atoxigenic biocontrol agents. (Abstr.) Phytopathology 107:S129.

Jaime, R., Foley, M., Antilla, L., and Cotty, P. J. 2012. Long-term and area-wide influences of atoxigenic strain biotrontrol technology for aflatoxin contamination. (Abstr.) Phytopathology 102:S4.58

Kamimura, H., Nishijima, M., Yasuda, K., Ushiyama, H., Tabata, S., Matsumoto, S., and Nishima, T. 1985. Simple, rapid cleanup method for analysis of aflatoxins and comparison with various methods. J. Assoc. Off. Anal. Chem. 68:458-461.

Liu, Y., Chang, C.-C. H., Marsh, G. M., and Wu, F. 2012. Population attributable risk of aflatoxin-related liver cancer: Systematic review and meta-analysis. Eur. J. Cancer 48:2125-2136.

Liu, Y.-C., Di, P., Chen, S.-H., and DaMassa, J. 2018. Relationships of rainy season precipitation and temperature to climate indices in California: Longterm variability and extreme events. J. Clim. 31:1921-1942.

Magan, N., Medina, A., and Aldred, D. 2011. Possible climate-change effects on mycotoxin contamination of food crops pre- and postharvest. Plant Pathol. 60: $150-163$.

Mauro, A., Battilani, P., Callicott, K. A., Giorni, P., Pietri, A., and Cotty, P. J. 2013. Structure of an Aspergillus flavus population from maize kernels in northern Italy. Int. J. Food Microbiol. 162:1-7.

Mauro, A., Battilani, P., and Cotty, P. J. 2015. Atoxigenic Aspergillus flavus endemic to Italy for biocontrol of aflatoxins in maize. BioControl 60:125-134

Mehl, H. L., and Cotty, P. J. 2010. Variation in competitive ability among isolates of Aspergillus flavus from different vegetative compatibility groups during maize infection. Phytopathology 100:150-159.

Mehl, H. L., Jaime, R., Callicott, K. A., Probst, C., Garber, N. P., Ortega-Beltran, A., Grubisha, L. C., and Cotty, P. J. 2012. Aspergillus flavus diversity on crops and in the environment can be exploited to reduce aflatoxin exposure and improve health. Ann. N. Y. Acad. Sci. 1273:7-17.

Nesci, A., and Etcheverry, M. 2002. Aspergillus section Flavi populations from field maize in Argentina. Lett. Appl. Microbiol. 34:343-348.

Ortega-Beltran, A., and Cotty, P. J. 2018. Frequent shifts in Aspergillus flavus associated with maize production in Sonora, Mexico. Phytopathology 108: $412-420$

Ortega-Beltran, A., Luo, Y., and Michailides, T. J. 2015. Use of propidium monoazide and qPCR to quantify viable and nonviable conidia of Aspergillus flavus in almond soils. (Abstr.) Phytopathology 105. http://www.apsnet.org/ meetings/Documents/2015_meeting_abstracts/aps2015abP658.htm.

Ortega-Beltran, A., Moral, J., Pucket, R. D., Morgan, D. P., Cotty, P. J., and Michailides, T. J. 2018. Fungal communities associated with almond throughout crop development: Implications for aflatoxin biocontrol management in California. PLoS One 13:e0199127.

Palumbo, J. D., Mahoney, N. E., Light, D. M., Siegel, J. P., Pucket, R. D., and Michailides, T. J. 2014. Spread of Aspergillus flavus by navel orange worm (Amyelois transitella) on almond. Plant Dis. 98:1194-1199.

Papa, K. E. 1986. Heterokaryon incompatibility in Aspergillus flavus. Mycologia 78:98-101.

Picot, A., Doster, M., Islam, M.-S., Callicott, K. A., Ortega-Beltran, A., Cotty, P. J., and Michailides, T. J. 2018. Distribution and incidence of atoxigenic Aspergillus flavus VCG in tree crop orchards in California: A strategy for identifying potential antagonists, the example of almonds. Int. J. Food Microbiol. 265:55-64.

Picot, A., Ortega-Beltran, A., Puckett, R. D., Siegel, J. P., and Michailides, T. J. 2017. Period of susceptibility of almonds to aflatoxin contamination during development in the orchard. Eur. J. Plant Pathol. 148:521-531.

Probst, C., Bandyopadhyay, R., Price, L. E., and Cotty, P. J. 2011. Identification of atoxigenic Aspergillus flavus isolates to reduce aflatoxin contamination of maize in Kenya. Plant Dis. 95:212-218.

Probst, C., Njapau, H., and Cotty, P. J. 2007. Outbreak of an acute aflatoxicosis in Kenya in 2004: Identification of the causal agent. Appl. Environ. Microbiol. 73 2762-2764

RASFF. 2017. The rapid alert system for food and feed (RASFF)—Food and feed safety alerts. Online publication. https://ec.europa.eu/food/safety/rasff_en

Shenge, K. C., Mehl, H. L., and Cotty, P. J. 2017. Interactions among active ingredients of a multi-isolate aflatoxin biocontrol product. (Abstr.) Phytopathology 107:S5.131.

Snedecor, G., and Cochran, W. 1980. Statistical Methods. The Iowa State University Press, Ames.

Sumner, D. A., Matthews, W. A., Medellín-Azuara, J., and Bradle, A. 2014. The economic impacts of the California almond industry. A report prepared for the Almond Board of California. Online publication. http://aic.ucdavis.edu/ almonds/Economic\%20Impacts\%20of\%20California\%20Almond\% 20Industry_Full\%20Report_FinalPDF_v2.pdf

USEPA. 2003. Biopesticide Registration Action Document Aspergillus flavus AF36. Online publication. United States Environmental Protection Agency. https://www3.epa.gov/pesticides/chem_search/reg_actions/registration/ decision_PC-006456_3-Jul-03.pdf

USEPA. 2012. Amendment to Add Pistachio Uses to the Label of Biopesticide Aspergillus flavus AF36. Online publication. United States Environmental Protection Agency. https://www3.epa.gov/pesticides/chem_search/ppls/07169300001-20120229.pdf 
USEPA. 2017. Aspergillus flavus AF36; Amendment to an Exemption from the Requirement of a Tolerance. Online publication. United States Environmental Protection Agency. https://www.gpo.gov/fdsys/pkg/FR-2017-03-22/pdf/201705720.pdf

van Egmond, H. P., Schothorst, R. C., and Jonker, M. A. 2007. Regulations relating to mycotoxins in food. Anal. Bioanal. Chem. 389:147-157.

Warburton, M. L., and Williams, W. P. 2014. Aflatoxin resistance in maize: What have we learned lately? Adv. Bot. Article ID 352831.
Wu, F. 2004. Mycotoxin risk assessment for the purpose of setting international regulatory standards. Environ. Sci. Technol. 38:4049-4055.

Wu, F. 2015. Global impacts of aflatoxin in maize: Trade and human health. World Mycotoxin J. 8:137-142.

Yu, J., Chang, P.-K., Ehrlich, K., Cary, J., Bhatnagar, D., Cleveland, T., Payne, G., Linz, J., Woloshuk, C., and Bennett, J. 2004. Clustered pathway genes in aflatoxin biosynthesis. Appl. Environ. Microbiol. 70:12531262. 